\title{
Reactivation hazard mapping for ancient landslides in West Belgium
}

\author{
O. Dewitte ${ }^{1}$, C.-J. Chung ${ }^{2}$, and A. Demoulin ${ }^{1,3}$ \\ ${ }^{1}$ Department of Physical Geography and Quaternary, University of Liège, Allée du 6 Août, 2, Sart Tilman (Bât. B11), 4000 \\ Liège, Belgium \\ ${ }^{2}$ Geological Survey of Canada, 601 Booth Street, Ottawa, Ontario K1A 0E8, Canada \\ ${ }^{3}$ Research Associate of the Belgian National Fund for Scientific Research, Belgium
}

Received: 22 November 2005 - Revised: 28 April 2006 - Accepted: 3 May 2006 - Published: 21 July 2006

Part of Special Issue "Spatial prediction modeling in natural hazards and risk"

\begin{abstract}
Several examples in western Europe have shown that, at least for deep-seated rotational slides, reactivation of formerly slipped masses is a more frequent phenomenon than the occurrence of new landslides, therefore representing a higher hazard. We selected a study area comprised of 13 landslides located in the Flemish Ardennes (West Belgium) and predicted the hazard related to scarp retreat. The scarp reactivations were identified from the comparison of DTMs produced for 1952 and 1996. Robust results were obtained with the Gamma operator of a fuzzy set approach and a combination of geomorphic, topographic and land use data. We built first a prediction model from the relations linking the 1952-1996 retreat events to the conditioning parameters of 1952. The prediction rate of the resulting susceptibility map is estimated by a cross-validation procedure. We then applied the statistics of this model to the data of 1996 in order to produce a susceptibility map responding to the present-day conditions. Finally, we estimated the conditional probabilities of occurrence of future reactivations for the period 1996-2036.
\end{abstract}

\section{Introduction}

An important part of the landslide literature focuses on predicting and mapping where, sometimes also when, new landslides will occur within a landslide-prone area (Carrara et al., 1991; Soeters and van Westen, 1996; Guzzetti et al., 1999; Glade and Crozier, 2005). In other words, many maps try to localise future landslide occurrences. However, several examples, notably in Europe, show that reactivation of formerly slipped masses is a more frequent phenomenon, therefore representing a higher hazard (Ardizzone et al., 2005; Catani et al., 2005; Reichenbach et al., 2005). Yet, very few studies have yielded prediction maps of landslide reactivation hazard

Correspondence to: O. Dewitte

(odewitte@ulg.ac.be)
(Lee et al., 1998, 2001; Barredo et al., 2000; Vaunat and Leroueil, 2002; Chung and Glade, 2004). Moreover, they generally distinguish only active and inactive landslides without separating the hazards of reactivating either the headscarp or the landslide body itself. Based on the combination of stereophotogrammetric estimates of recent scarp movements and GIS-supported simulations using various sets of potential causal variables, the aim of our research is to propose a new approach to locate the parts of pre-existing landslide scarps most susceptible to reactivation. Strictly speaking, our study area corresponds thus to the main scarps of the landslides and the reactivated zones are those scarp parts undergoing renewed collapse. The prediction model proposed here refers to the "favourability function" approach proposed by Chung and Fabbri (1993). This probabilistic approach requires two assumptions: (1) the reactivation can be characterized by topographical, geological and environmental spatial data and (2) the future events will occur under the same circumstances similar to the past ones.

\section{Study area}

The study area belongs to the so-called Flemish Ardennes, a region extending over $\sim 430 \mathrm{~km}^{2}$ in western Belgium and affected by 135 big deep-seated past landslides (Fig. 1) (Ost et al., 2003, Van Den Eeckhaut et al., 2005). In the absence of any dating, Van Den Eeckhaut et al. (2005) assume that, because no recent written document describing the initiation of one of these large landslides has been found, they are at least 100 years old. Moreover, the study of similar ancient landslides located in eastern Belgium, in the Pays de Herve, pointed to a first episode of motion at $150 \pm 80$ A.D. (Demoulin et al., 2003). As in the Pays de Herve, the origin of the Flemish Ardennes landslides results probably from the combination of a seismic event occurring during a period of heavy rainfall (Demoulin et al., 2003; Ost et al., 2003).

Published by Copernicus GmbH on behalf of the European Geosciences Union. 


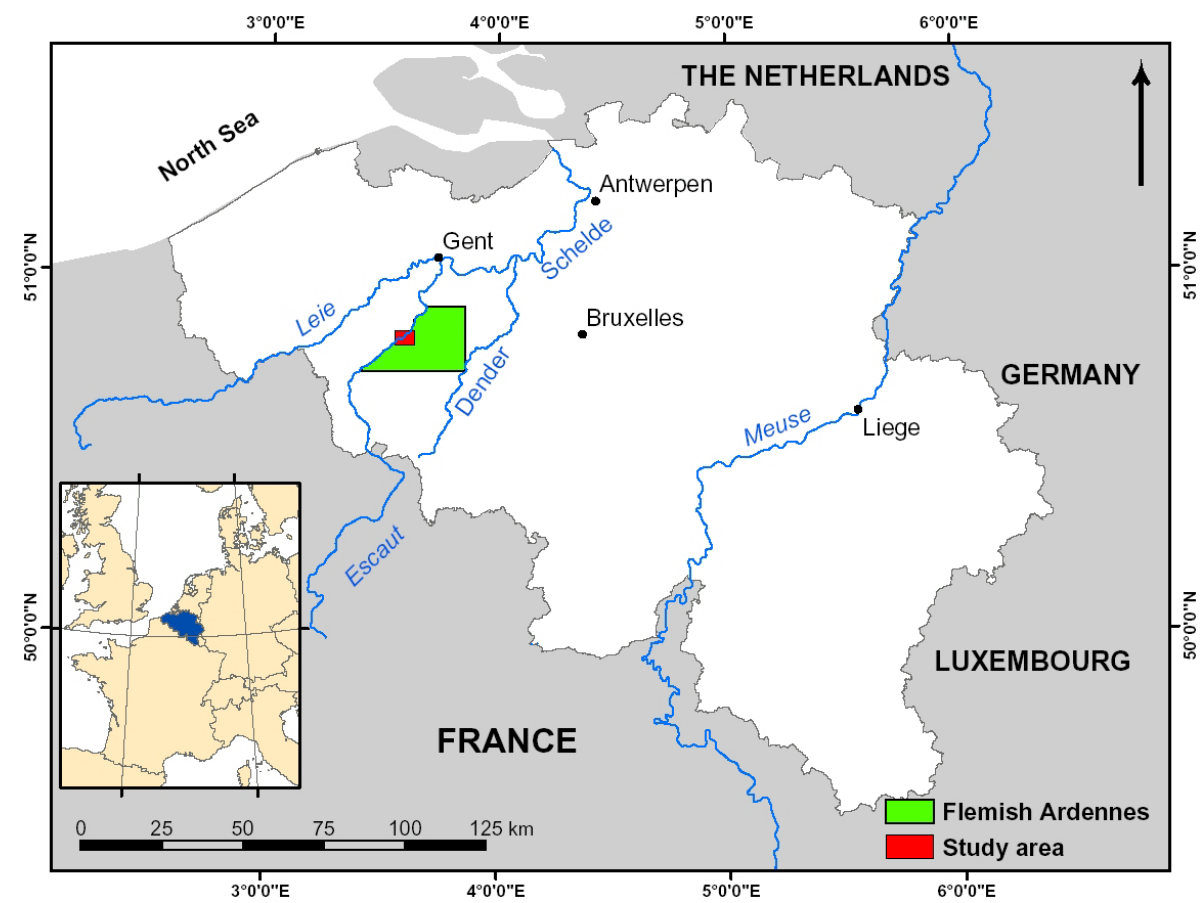

Fig. 1. Location map of the Flemish Ardennes and the study area.

Whereas no new deep-seated landslide is known to have occurred for decades, several reactivation episodes have been recently observed in this area (Ost et al., 2003; Dewitte and Demoulin, 2005; Van Den Eeckhaut et al., 2005). This is obviously due to the destructuring of slipped material and the presence of pre-existing shear surfaces, which considerably lower the shear strength of ancient landslides with respect to that of the original landslide-free slopes. In addition, it could be that the hierarchy of environmental factors determining a reactivation is somewhat different from that controlling a new slope failure.

To predict the hazard related to main scarp retreat, we selected a test area containing 13 landslides (Figs. 2 and 3). These landslides developed on two hills culminating between 75 and $85 \mathrm{~m}$ a.s.l. and situated along the river Schelde close to the town of Oudenaarde. In the north, the Leupegem hill is affected by 3 landslides. To the south, 10 landslides developed on the slopes of the Rotelenberg hill. The morphometric parameters of these landslides are presented in Table 1.

The landslides are developed in subhorizontal (dip to the north $<1^{\circ}$ ) Eocene sediments composed of alternating clays and clayey sands on which a perched water table can develop. Within these formations, the Aalbeke Member consists of 10-m-thick homogeneous blue massive clays, and has been recognized as the layer most sensitive to landsliding (Fig. 2).

One of the presently most active and damaging reactivated landslides of the Flemish Ardennes (landslide 1, Figs. 2 and 3b) was reactivated in February 1995 after a period of heavy rainfall in December 1994 and January 1995. Indeed, this is presently demonstrated to trigger reactivations of old deepseated rotational landslides developed in clayey sediments (Corominas and Moya, 1999; Polemio and Sdao, 1999; Fiorillo, 2003; Demoulin and Glade, 2004). This reactivation event, with a horizontal scarp retreat of up to $19 \mathrm{~m}$, was particularly important for the area. However, several morphological features like fresh scarps and tilted trees bear witness to recent reactivation of other landslides too (Dewitte, 2006).

\section{Data used in the modelling}

The first step in our data collection was to localise the reactivated parts of the 13 main scarps. To do this, DTMs (Digital Terrain Models) of the Leupegem and Rotelenberg hills (Fig. 2) were generated in the form of a $2 \mathrm{~m} \times 2 \mathrm{~m}$ grid for 1952 and 1996 by digital stereophotogrammetry using aerial photographs (Dewitte and Demoulin, 2005). From the comparison of these DTMs for the two epochs, we identified 14 areas of scarp retreat exceeding $2 \mathrm{~m}$ (Fig. 4). This value of lateral displacement defines the $95 \%$ confidence level derived from the interval $\sim 0.5 \mathrm{~m}$ RMS error on the DTMs (Dewitte and Demoulin, 2005). In consideration to the recent observed main scarp reactivations (after 1996), the reactivated parts were manually divided into 26 scarp segments of similar length (about $30 \mathrm{~m}$ ) which we consider to correspond to the unit length of a reactivation event (i.e. an occurrence).

Because of the alteration of the data due to the conversion of the scarp lines (i.e. the top line of the main scarp) to the raster format, these lines of pixels were not used as such 
Table 1. Morphometric parameters of the 13 deep-seated rotational landslides considered in the study.

\begin{tabular}{|c|c|c|c|c|c|c|c|}
\hline Landslide & $\begin{array}{l}\text { Area* } \\
\text { (ha) }\end{array}$ & $\begin{array}{l}\text { Headscarp height* } \\
(\mathrm{m})\end{array}$ & $\begin{array}{l}\text { Landslide height" } \\
\text { (m) }\end{array}$ & $\begin{array}{c}\text { Slope angle* } \\
\left({ }^{*}\right)\end{array}$ & $\begin{array}{l}\text { Length* } \\
(\mathrm{m})\end{array}$ & $\begin{array}{l}\text { Estimated volume** } \\
\qquad\left(10^{3} \mathrm{~m}^{3}\right)\end{array}$ & $\begin{array}{l}\text { Headscarp length } \\
\text { (m) }\end{array}$ \\
\hline 1 & 8,8 & 9 & 52 & 8 & 372 & 2008 & 392 \\
\hline 2 & 2,7 & 8 & 31 & 8 & 236 & 457 & 343 \\
\hline 3 & 2,3 & 9 & 27 & 8 & 185 & 218 & 128 \\
\hline 4 & 2,5 & 7 & 21 & 9 & 133 & 197 & 270 \\
\hline 5 & 9,5 & 9 & 50 & 8 & 345 & 1458 & 184 \\
\hline 6 & 7,3 & 8 & 57 & 8 & 408 & 941 & 80 \\
\hline 7 & 9,3 & 8 & 62 & 8 & 439 & 1669 & 247 \\
\hline 8 & 6,0 & 8 & 53 & 9 & 352 & 1161 & 115 \\
\hline 9 & 5,5 & 7 & 47 & 7 & 375 & 1047 & 218 \\
\hline 10 & 9,0 & 7 & 51 & 5 & 575 & 2372 & 289 \\
\hline 11 & 6,4 & 9 & 41 & 7 & 357 & 1249 & 335 \\
\hline 12 & 4,6 & 9 & 49 & 8 & 338 & 950 & 279 \\
\hline 13 & 1,9 & 8 & 41 & 9 & 264 & 253 & 220 \\
\hline$\overline{\text { Mean }}$ & 5,8 & 8 & 45 & 8 & 337 & 1075 & 240 \\
\hline
\end{tabular}

*From Dewitte and Demoulin (2005). The headscarp height is the maximum height of the scarp; the landslide height represents the difference is elevation between the crown and the tip of the landslide; the length is the horizontal component of the overall runout of the landslide.

** The estimated volume represents a mean value obtained between the different volumes computed by Dewitte and Demoulin (2005).

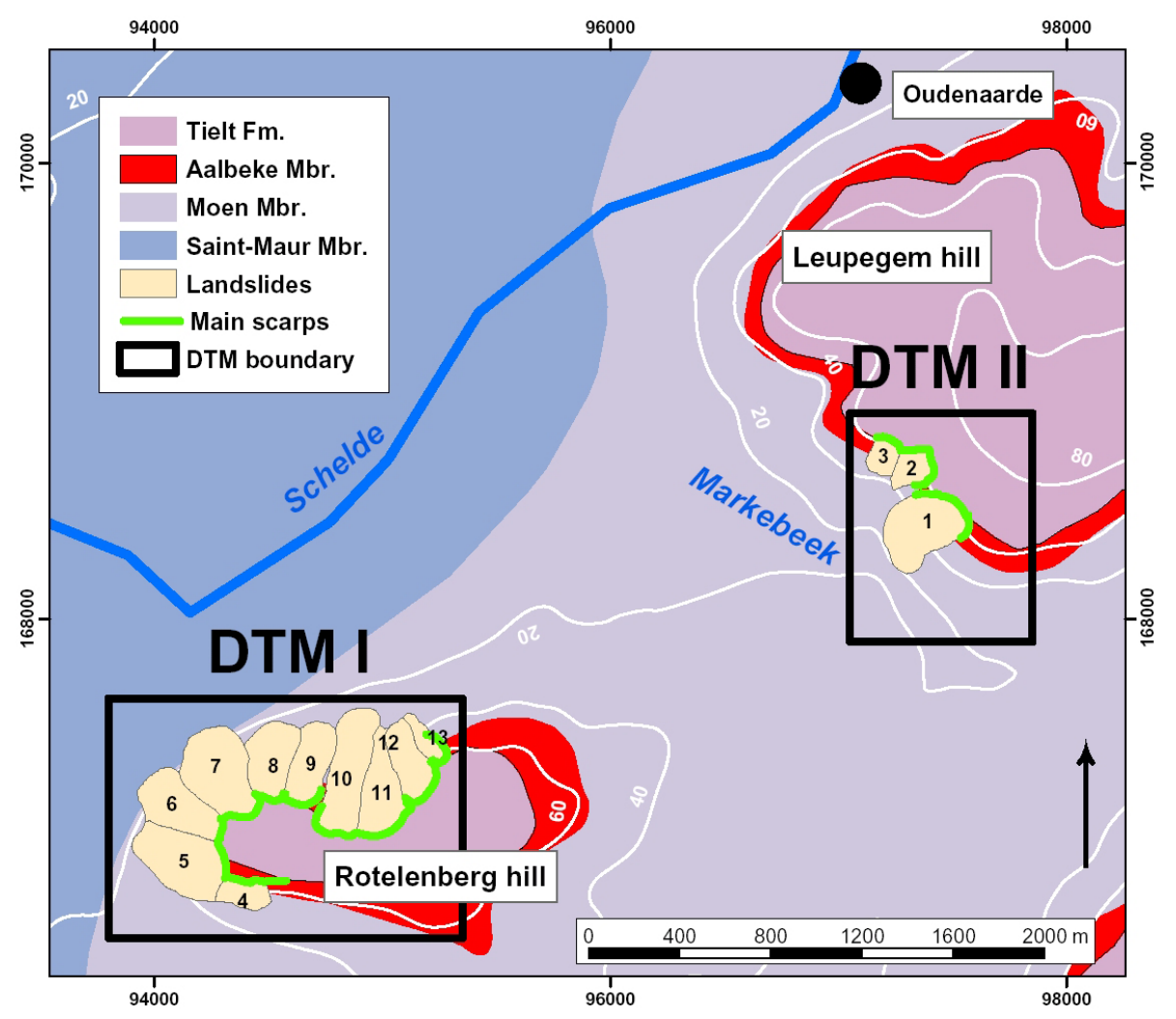

Fig. 2. Location of the two hills of the study area with the lithological setting and the boundaries (scars) and the main scarps of the 13 landslides considered in the analysis. The quadrangles I and II locate the two DTMs used in the prediction. 


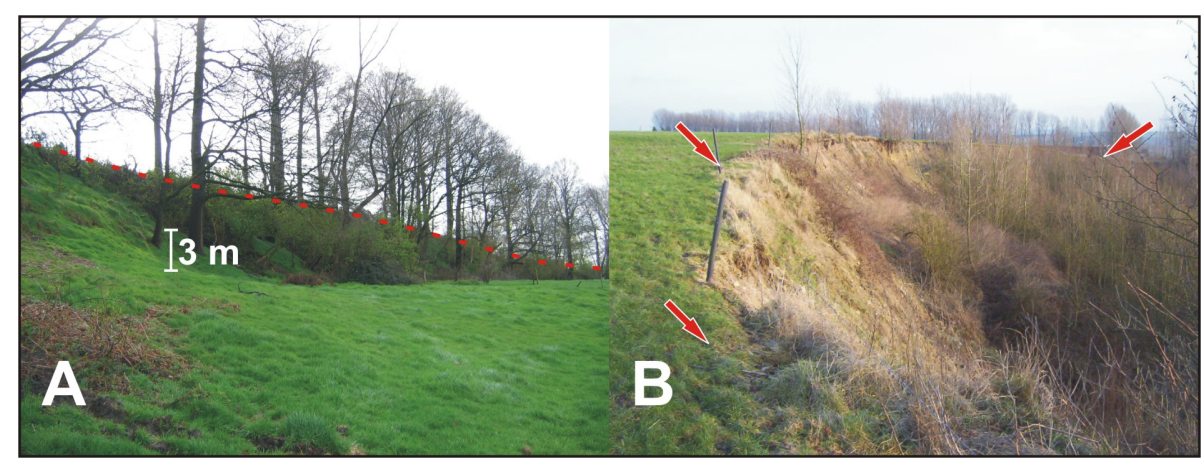

Fig. 3. Examples of main scarps. (A) View towards the SE of the landslide 5 main scarp (Fig. 2) (Rotelenberg hill, April 2004). The red dashed line shows the main scarp which has been stable since 1952. (B) View towards the SE of the February 1995 reactivated main scarp of the Hekkebrugstraat landslide (landslide 1 in Fig. 2) (Leupegem hill, February 2003). The 9-m-height fresh scarp (red arrows) indicates that the head of this landslide has been still active since 1995 .

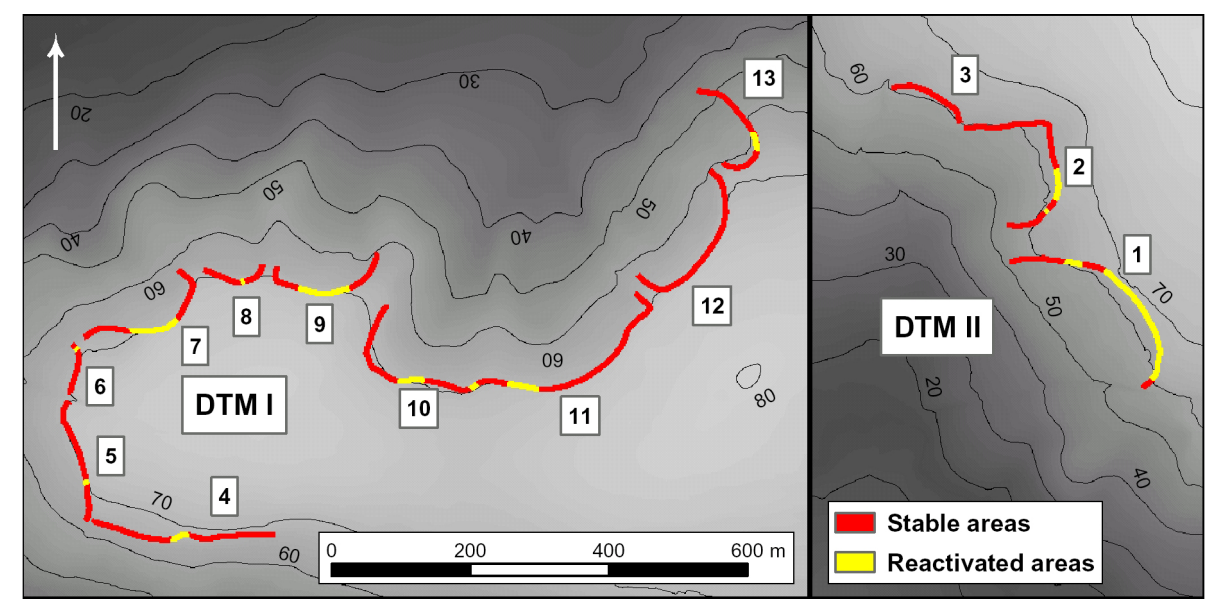

Fig. 4. Study area with the 14 areas of scarp retreat (reactivated areas) between 1952 and 1996.

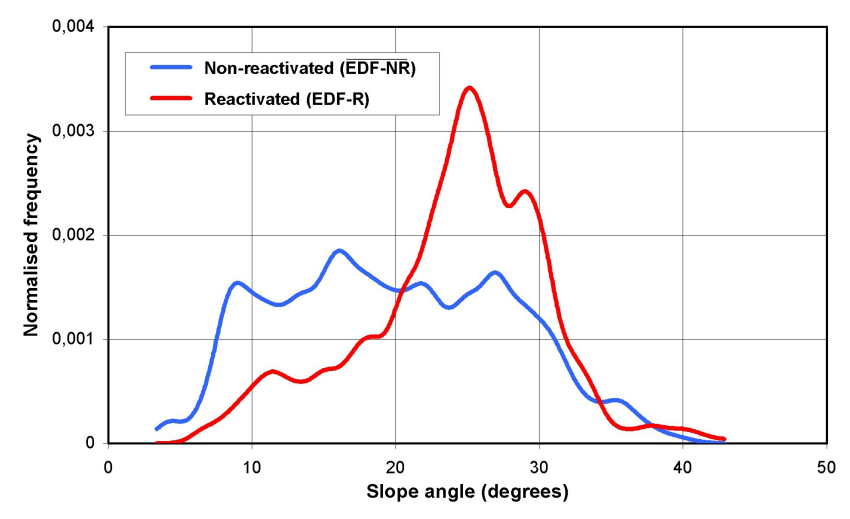

Fig. 5. Empirical frequency distribution functions of the slope angles within reactivated and non-reactivated pixel population.

in the prediction. We chose to define the study area as the first lines of pixels downslope of the top of the scarps and located on the visible part of the surface of rupture, which corresponds fairly well to the real scarp area. The 26 reac- tivated scarp segments were used as the dependent variable in the modelling. In total, the study area covers 6293 pixels with $2 \mathrm{~m}$ resolution of which 1268 have been reactivated. We also considered 13 independent variables as potential conditioning parameters in the modelling, all of them taken at the same resolution (2 m) (Table 2).

Before modelling, a qualitative evaluation of the contribution of each quantitative (or continuous) variable to landslide reactivation was performed by comparing two empirical distribution functions (EDFs), respectively for the reactivated (EDF-R) and non-reactivated (EDF-NR) pixels as shown in Fig. 5 for the slope angle data layer. The same evaluation was carried out for the two qualitative (or thematic) variables (land use and lithology) by comparing a pair of frequency tables. Based on this analysis, the data layers slope angle, slope aspect and elevation seem to best explain the main scarp reactivation (Dewitte, 2006).

The computed values of the EDFs and the thematic frequencies will yield the favourability values necessary to the prediction. 
Table 2. Description of the 13 input data layers used as conditioning parameters in the modelling.

\begin{tabular}{|c|c|c|c|c|}
\hline Variable & Unit & Type* & Original data** & Description \\
\hline Elevation & $\mathrm{m}$ & 1 & DTMs & Altitude asl \\
\hline Slope angle & Degree & 1 & DTMs & Slope angle \\
\hline Slope aspect & Degree & 1 & DTMs & $\begin{array}{l}\text { Slope direction measured in positive degrees from } 0 \text { to } 359.9 \text { clockwise from } \\
\text { north }\end{array}$ \\
\hline Flow accumulation & Pixel & 1 & DTMs & $\begin{array}{l}\text { Grid of accumulated flow to each cell. The values correspond to the number of } \\
\text { cells that flows into each downslope cell. So, output cells with a high flow } \\
\text { accumulation are areas of concentrated flow }\end{array}$ \\
\hline Focal flow & Pixel & 1 & DTMs & $\begin{array}{l}\text { Local flow concentration involving the surrounding } 8 \text { pixels. Its resulting } \\
\text { values measure flow into, and not out of a cell }\end{array}$ \\
\hline Profile curvature & $1 / 100 \mathrm{~m}$ & 1 & DTMs & $\begin{array}{l}\text { Vertical curvature of the surface at each pixel center. The profile curvature } \\
\text { represents the rate of change of slope for each pixel in the vertical plane of } \\
\text { maximum slope }\end{array}$ \\
\hline Planform curvature & $1 / 100 \mathrm{~m}$ & 1 & DTMs & $\begin{array}{l}\text { Curvature of the surface perpendicular to the slope direction. The plan } \\
\text { curvature shows the bending of the surface perpendicular to the slope } \\
\text { direction. Together plan and profile curvatures control the flow of water in and } \\
\text { out of slopes }\end{array}$ \\
\hline $\begin{array}{l}\text { Distance from } \\
\text { stream network }\end{array}$ & $\mathrm{m}$ & 1 & DTMs & $\begin{array}{l}\text { Calculated as an Euclidian distance from the stream channel network } \\
\text { simulated based on flow accumulation data. Each pixel with a flow } \\
\text { accumulation value exceeding } 2000 \text { pixels was classified as a stream. The use } \\
\text { of this threshold value resulted in a drainage area of } 8 \text { ha as the one observed } \\
\text { for incipient gully development in Central Belgium (Poesen et al., 2003) }\end{array}$ \\
\hline Land use & Class & 2 & Orthophotos & 4 classes: cultivation, meadow, forest, built areas (roads and houses) \\
\hline Lithology & Class & 2 & Rock type map & $\begin{array}{l}4 \text { rock types: Tielt Formation (clayey sand alternating with clay layers), } \\
\text { Aalbeke Member (clay), Moen Member (clayey coarse silt to fine sand with } \\
\text { clay layers), Saint-Maur Member (silty clay) }\end{array}$ \\
\hline $\begin{array}{l}\text { Distance from } \\
\text { cultivation }\end{array}$ & $\mathrm{m}$ & 1 & Orthophotos & $\begin{array}{l}\text { Euclidian distance from the nearest cultivations located upstream of the main } \\
\text { scarps }\end{array}$ \\
\hline $\begin{array}{l}\text { Distance from } \\
\text { Aalbeke Member }\end{array}$ & $\mathrm{m}$ & 1 & Lithological map & Euclidian distance from the Aalbeke clays most sensitive to landsliding \\
\hline Vegetation index & $\mathrm{Pixel} / \mathrm{m}$ & 1 & Orthophotos, DTMs & $\begin{array}{l}\text { Flow accumulation through the cultivated areas located upstream of the main } \\
\text { scarp and weighted by the lenght of the flow }\end{array}$ \\
\hline
\end{tabular}

* Type 1 means quantitative variable and type 2 qualitative variable.

** Both DTMs and orthophotos of 1952 and 1996 were used to build the variables.

\section{Methodology}

Different modelling strategies based on the empirical frequency distribution functions and the thematic frequencies referred in Sect. 3 have been tested using the Spatial Prediction Modeling System Mapping software (SPMS, 2003): the fuzzy set, the likelihood ratio, the linear and logistic regression and the Bayesian predictive discriminant models. The results of the different models rely on various sets of selected geomorphic, topographic and land use data presented in Table 2. Considering prediction-rate curves to measure the model performance, empirical handlings of the variables revealed that combinations of four or five data layers were generally most appropriate to the prediction. Moreover, as already shown for the qualitative evaluation of the EDFs, these handlings stressed the significant role of the slope aspect in the reactivation process (Dewitte, 2006). We decided therefore not consider the linear and logistic regression and the Bayesian predictive discriminant models because they do not allow the use of circular data layers such as the slope aspect (SPMS, 2003; Chung and Fabbri, 2005).

Two robust and reliable predictions were obtained with the fuzzy set approach using the fuzzy Gamma operator. The fuzzy set prediction model combines the favourability values by using the fuzzy set theory of Zadeh $(1965,1968$, 1978). Numerous studies have used GIS and statistics for landslide susceptibility and hazard mapping, but mapping attempts using fuzzy set approaches are few (e.g., Binaghi et al., 1998; Chung et Fabbri, 2001; Chi et al., 2002; Ercanoglu and Gokceoglu, 2004; Tangestani, 2004).

The idea behind fuzzy logic, which was firstly introduced by Zadeh (1965), is to consider how much a spatial object 
belongs to a set. Fuzzy set theory can thus be considered as an extension of ordinary set theory (based on crisp sets). In classical set theory, an object belongs or does not belong to a set which contains only 0 and 1 values as degrees of membership. In fuzzy set theory, membership can take on any continuous value in the real number interval $[0,1]$, reflecting the degree of membership. When the degree of membership reaches 1 , the element completely belongs to the set. Lower degrees express a partial membership to the set, down to the value of 0 which indicates no-belonging. A fuzzy set can thus be explained as a set containing elements that have varying degrees of membership in the set (Zimmermann, 1991; Klir and Yuan, 1995).

In this landslide reactivation susceptibility mapping, membership values (i.e. favourability values) ranging from 0 to 1 are to be given to each pixel of each input data layer. To do this, we have computed a membership function $\mu(x)$ for each input data layer as follow:

$\mu(x)=\frac{\mathrm{EDF}-\mathrm{R}}{\mathrm{EDF}-\mathrm{R}+\overline{\mathrm{EDF}-\mathrm{NR}}}$

where EDF-R is the empirical distribution function of the reactivated areas and $\overline{\text { EDF-NR }}$ is the empirical distribution function of the non-reactivated areas. When there are two or more maps with fuzzy membership functions for the same set, as currently, a variety of operators can be employed to combine the membership values (An et al., 1991; Zimmermann, 1991; Bonham-Carter, 1994; Moon 1998).

Following Chung and Fabbri (2001), Chi et al. (2002) and Tangestani (2004), we used here the fuzzy Gamma operator which was defined by Zimmermann and Zysno (1980) as a combination of the fuzzy algebraic product and the fuzzy algebraic sum. The joint membership function $\mu_{S}(x)$ of the fuzzy set $\mathrm{S}$ for a particular pixel $\mathrm{x}$ is defined as:

$\mu_{S}(x)=\left[\mu_{\text {Sproduct }}(x)\right]^{1-\gamma} \times\left[\mu_{\text {Ssum }}(x)\right]^{\gamma}$

where $\gamma$ is a parameter chosen in the range $[0,1]$, and the fuzzy algebraic product and fuzzy algebraic sum are calculated using Eqs. (3) and (4), respectively:

$\mu_{\text {Sproduct }}(x)=\left[\prod_{j=1}^{m} \mu_{S_{j}}(x)\right]$

$\mu_{S \text { sum }}(x)=\left[1-\prod_{j=1}^{m}\left(1-\mu_{S_{j}}(x)\right)\right]$

where $\mu_{S_{j}}(x)$ is the fuzzy membership function for the $j$-th map, and $j=1,2, \ldots, \mathrm{m}$ are the maps that have to be combined. The Gamma operator is a useful tool for calculating a range of values going from a minimum, corresponding to the algebraic product $(\gamma=0)$, to a maximum, corresponding to the algebraic sum $(\gamma=1)$. Though it has been shown that fuzzy operators depend very much on the type of spatial data (Moon, 1998; Chi et al., 2002), we decided to use here only the Gamma operator with $\gamma=0.5$. This choice of $\gamma$ value ensures a compromise between the "decreasing" effects of the fuzzy algebraic product and the "increasing" effects of the fuzzy algebraic sum.

\section{Results}

The first model we obtained with this Gamma operator (hereafter called APIF) combines 4 data layers: slope Aspect, Planform curvature, Vegetation index and Focal flow. The second one (ASEPV) was built from five layers: slope Aspect, Slope angle, Elevation, Planform curvature and Distance from cultivation. The first model results from an empirical selection of the variables considering the prediction rate of each data layer individually, whereas the second model is a more heuristic combination based on the geomorphological expertise and the qualitative analysis of the empirical distribution functions. With respect to their prediction-rate curve, the first model appears to be the most appropriate one to predict the main scarp reactivation (Fig. 7). A three-step procedure has been used to obtain the prediction maps of the APIF model that we present hereafter.

\subsection{Step 1: landslide susceptibility mapping on the basis of the 1952 data}

In landslide hazard studies, the prediction is generally made from past occurrences and conditioning parameters related to a more recent epoch. These data do not represent exactly the conditions that prevailed before the landslide occurred. Consequently, the results might involve factors closer to consequences than causes of the movements. In this research, we built the prediction model from the relations linking the 1952-1996 scarp retreat events to the conditioning parameters of 1952. We took thus the causal factors which existed before the reactivations, i.e. the parameters which were connected to the causes and not the consequences of the reactivations. The computed values of reactivation susceptibility, which may range from 0 to 1 , were sorted in decreasing order and grouped into 200 classes, so that each class covers $0.5 \%$ of the total study area (thus contains $0.5 \%$ of the total number of pixels in the study area) (Fig. 6). The class numbered 200 corresponds to the $0.5 \%$ highest scores, i.e. to the $0.5 \%$ most hazardous area.

In prediction modelling, the cross-validation of the results is a mandatory step to assess the accuracy and the reliability of the model. As stressed by Chung and Fabbri (2003), to validate a prediction image for future events, time partitioning is the most natural and convincing strategy. In our case, because there is only one time interval of past occurrences, a sequential spatial partitioning of the occurrences was performed. The prediction rate of the resulting susceptibility map was estimated by a spatial cross-validation procedure sequentially excluding 2 of the 26 reactivated scarp 


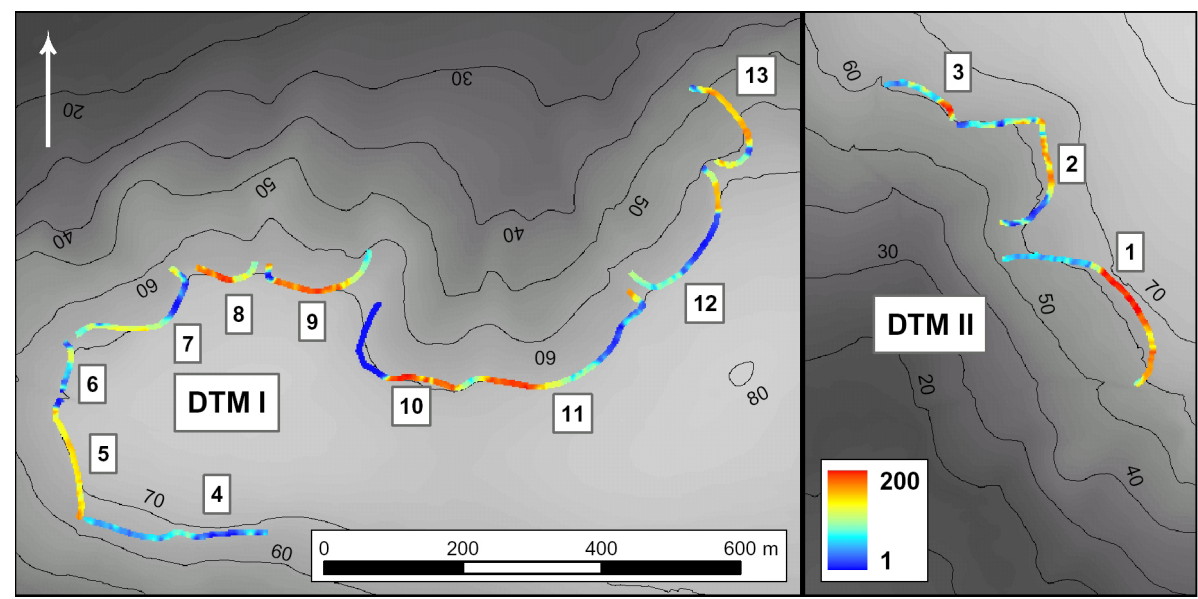

Fig. 6. Susceptibility map of the landslide reactivation hazard obtained from the 1952 data layers: slope Aspect, Planform curvature, Vegetation index and Focal flow (APIF). The class 200 corresponds to the $0.5 \%$ most hazardous area.

segments (Fig. 7). This experiment was repeated 13 times in order to consider only once each of these 26 occurrences. For this validation, we decided that, for a prediction to be considered successful, at least $25 \%$ of each occurrence (i.e. $25 \%$ of its pixels) not used to predict, had to lie within a predicted reactivation-prone area. We then obtained, for each of the occurrences, the portion of the study area necessary to be selected to predict it. The prediction-rate curves presented in Fig. 7 were plotted from these 26 values. For each curve, the smallest portion was first placed on the $\mathrm{x}$-axis with its corresponding reactivated area on the y-axis. Afterwards, the second smallest portion value was plotted on the graph. The second $\mathrm{Y}$ value associated with this portion is the sum of the two first reactivated scarp areas. The same operation was performed with the third smallest portion, etc.

\subsection{Step 2: modelling on the basis of 1996 data}

Because we were interested in predicting future occurrences of reactivation, we needed to build our model on the current (i.e., 1996) state of the conditioning variables.

We applied the statistics of the model computed in Step 1 to the data of 1996 (which include significant changes in land use) to produce a susceptibility map responding to the present-day conditions (Fig. 8). The susceptibility scores presented were computed similarly to what was done in Step 1.

Of course, we had no means to validate this second map owing to the fact that no quantitative information on reactivations developed after 1996 was available. However, as the study area of 1996 is very similar to the one of 1952, the reliability of the 1996 prediction should be approximately the same as that of 1952 .

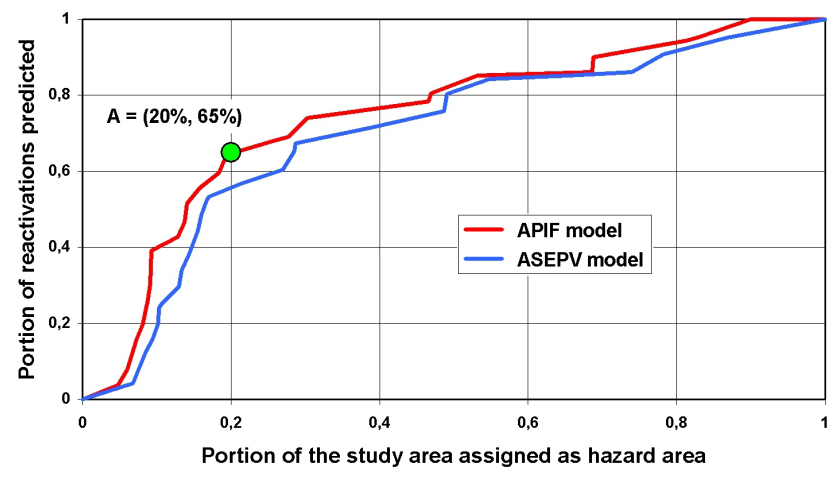

Fig. 7. Prediction-rate curves obtained by cross-validation. For the APIF model, the highest hazardous $20 \%$ of the study area contain $65 \%$ of the predicted reactivations (point A).

\subsection{Step 3: probability of occurrence of future reactivations}

Finally, we estimated the conditional probabilities of occurrence of future reactivations for the period 1996-2036 (Fig. 9) by using the prediction-rate table of the model obtained from Step 1. The probability that a pixel, $\mathrm{x}$, in a given hazard class, will be affected by a future scarp retreat is estimated by the following equation as discussed in Chung and Fabbri (2005) and Chung (2006):

$$
\hat{P} x=1-\left[1-p_{h}\right]^{\frac{n_{r}}{n_{h}}}
$$

With $\mathrm{n}_{h}=$ the cumulative number of pixels in the hazard classes whose levels are higher or equal to the class; $\mathrm{n}_{r}=$ the number of pixels in the expected future reactivations; and $\mathrm{p}_{h}$ the cumulative portion of reactivations of the validation group in the hazard classes whose levels are higher or equal to the class, obtained from the prediction-rate presented in Fig. 7. To calculate the conditional probabilities of the scenario 1996-2036 (Fig. 9), we supposed that the scarps were 


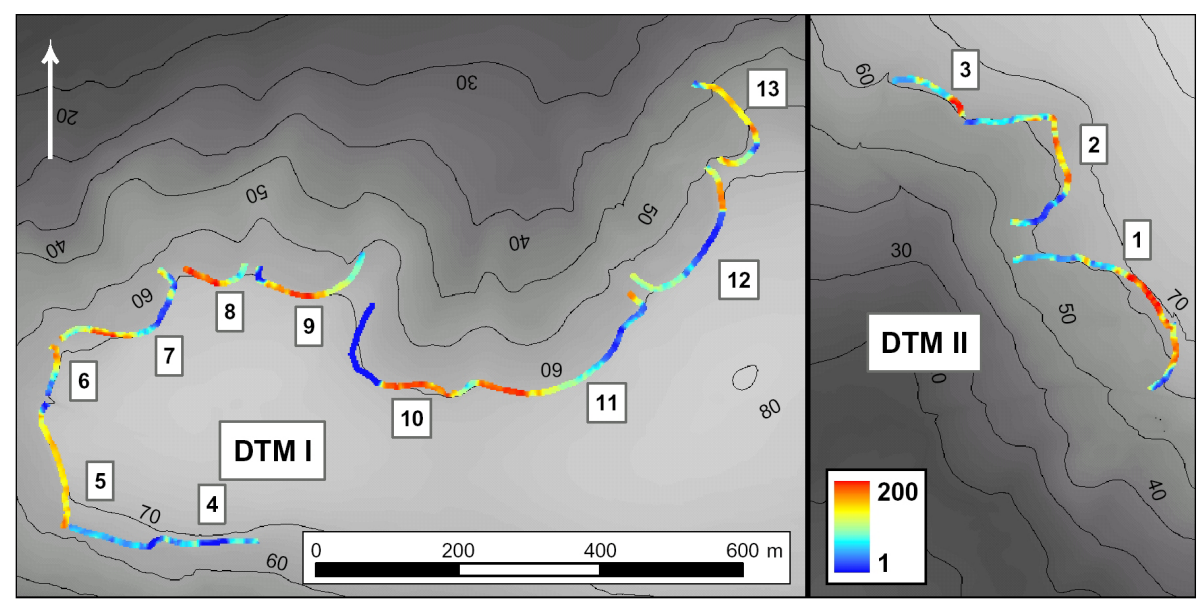

Fig. 8. Susceptibility map of the landslide reactivation hazard obtained with the statistics of the 1952 APIF model and the 4 following 1996 layers: slope Aspect, Planform curvature, Vegetation index and Focal flow (APIF). The class 200 corresponds to the $0.5 \%$ most hazardous area.

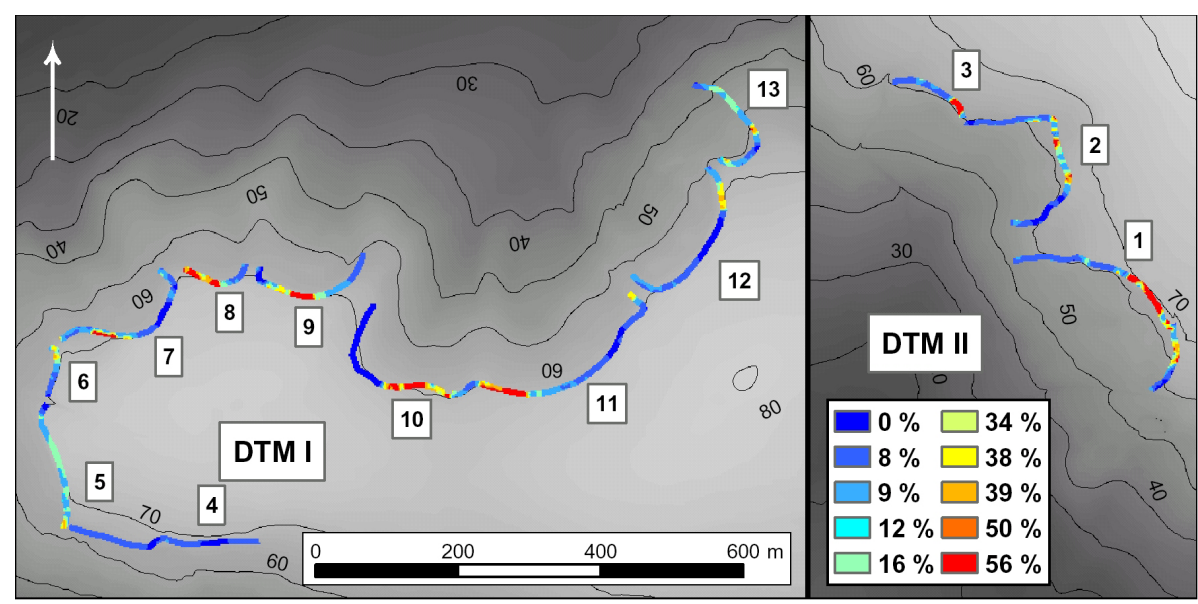

Fig. 9. Map of the conditional probabilities of occurrence of future reactivations for the period 1996-2036 (APIF model).

retreating at a constant mean rate and thus the same area ( $\mathrm{n}_{r} \sim 1200$ pixels) as that observed from 1952 to 1996 would be affected by reactivation during the next 40 years.

According to the definition notably used by Soeters and van Westen (1996) and initially proposed by Varnes (1984) who defined the landslide hazard as "the probability of occurrence of a potentially damaging phenomenon within a specified period of time and within a given area", this probability map showing the occurrence of future reactivations represents a hazard map. Nevertheless, we remain conscious that our map does not correspond to the amended definition of Guzzetti et al. (1999) which include the magnitude of the event.

\section{Discussion}

Considering the prediction-rate curves, the two models presented here (APIF and ASEPV) are only marginally different (Fig. 7). Basically, the validation provides an estimate of the ability of a model to predict correctly the spatial occurrence of new reactivations but it does not say anything on how realistic the model is, so that there is no way to choose between various models other than to invoke heuristic reasons (Oreskes et al., 1994).

Both models include the slope aspect layer depicted here as one of the most important parameter associated with the main scarp reactivation. The major role of this variable had to be understood as the effects it exerts over the rainfall amounts brought by dominant winds and to a lesser extent the solar radiation which influences soil humidity. 
From the geomorphological point of view, the APIF model (Figs. 6, 8 and 9) may appear more realistic than the ASEPV model. Indeed, it not only highlights the significant role played by the flow concentration, which is the major cause of the reactivations observed notably in landslide 1, but it also stresses the importance of the cultivated areas located upstream of the headscarp in increasing the runoff towards the landslide crown. Field observations also confirm that some of the reactivation movements are clearly related to the development of cultivated areas upstream of the main scarp. Mainly in winter, the bare soils favour flow concentration toward the landslides. Moreover, the "slope angle" variable, which does not appear as such in the model, is taken into account indirectly by the variable "focal flow" that evaluates the eight immediate neighbours of each pixel (Table 2).

As for the ASEPV model, it includes explicitly the slope angle variable and the influence of cultivated areas upstream of the scarp (V: distance from cultivation). Its comparative theoretical weakness lies probably in the much more remote account it takes of the flow concentration, through the use of $\mathrm{P}$, the planform curvature variable. It should however be noted that ascribing a prominent role to the flow concentration variable $\mathrm{F}$ amounts to assuming that runoff prevails over percolation in triggering headscarp retreat, which is probably true only when bare (cultivated) soils undergoing winter rainfall are located in direct contact with the scarp.

In summary, although the observed reactivations in landslide 1 from 1996 to the present time have been better predicted by the APIF model, we remain cautious in stating that one model is closer to the geomorphological reality than the other. The different sets of selected variables could as well result from a marginal precedence between more or less redundant variables.

\section{Conclusions}

This study demonstrates the feasibility of assessing the landslide reactivation hazard in a robust and reliable way. A set of 26 main scarp reactivation events covering $\sim 1300$ pixels was used to fit the model with 4 variables: slope aspect, planform curvature, vegetation index and focal flow. The predictionrate curve (Fig. 7) shows that if we select $20 \%$ of the most hazardous areas, we predict about $65 \%$ of the future landslide reactivations.

The next step in the research will be to extend this approach to a larger area, working then at a coarser resolution, and looking at whether the various variables will keep the same relative importance in the landslide reactivation prediction.

We have focused here only on the headscarps without taking into account the existing kinematic data of the whole mass of the landslides (Dewitte and Demoulin, 2005). It could be interesting to use the latter information to weight in some way the scarp retreat data, and especially to see whether the parameters controlling the movements of the landslide body are the same as those controlling the scarp reactivation.

Acknowledgements. We are grateful to A. G. Fabbri and four anonymous referees for reviewing an earlier version of the manuscript. Their critical reviews have improved the readability and content of the manuscript.

Edited by: T. Glade

Reviewed by: A. Fabbri and four other referees

\section{References}

An, P., Moon, W. M., and Rencz, A.: Application of fuzzy set theory to integrated mineral exploration, Can. J. Explor. Geophys., 27, 1-11, 1991.

Ardizzone, F., Cardinali, M., Galli, M., Guzzetti, F., and Reichenbach, P.: Validation of a landslide inventory map and of landslide risk assessments using event inventory maps, Geophys. Res. Abstr., 7, 2005.

Barredo, J. I., Benavides, A., Hervás, J., and van Westen, C. J.: Comparing heuristic landslide hazard assessment techniques using GIS in the Tirajana basin, Gran Canaria Island, Spain, Int. J. Appl. Earth Observation and Geoinformation, 2, 9-23, 2000.

Binaghi, E., Luzi, L., Madella, P., Pergalani, F., and Rampini, A.: Slope instability zonation: a comparison between certainty factor and fuzzy Dempster-Shafer approaches, Nat. Hazards, 17, 7797, 1998.

Bonham-Carter, G. F.: Geographic Information System for geoscientists: modelling with GIS, Computer Methods in the Geosciences, 13, Pergamon, New York, 1994.

Carrara, A., Cardinali, M., Detti, R., Guzzetti, F., Pasqui, V., and Reichenbach, P.: GIS techniques and statistical models in evaluating landslide hazard, Earth Surf. Processes and Landforms, 16, 427-445, 1991.

Catani, F., Bartolomei, A., Kukavicic, M., Tofani, V., Casagli, N., and Sulli, L.: Unraveling hidden landslides in the Arno river basin (Italy) through neural networks, Geophys. Res. Abstr., 7, 2005.

Chi, K.-H., Park, N.-W., and Chung, C. F.: Fuzzy logic integration for landslide hazard mapping using spatial data from Boeun, Korea, ISPRS congress 2002, Commission IV, Geospatial Theory, Processing and Applications, Ottawa, 2002.

Chung, C. F.: Using likelihood ratio functions for modeling the conditional probability of occurrence of future landslides for risk assessment, Computers \& Geosciences, in press, 2006.

Chung, C. F. and Fabbri, A. G.: The representation of geoscience information for data integration, Nonrenewable Resources, 2, 122139, 1993.

Chung, C. F. and Fabbri, A. G.: Prediction models for landslide hazard using a fuzzy set approach, in: Geomorphology and Environmental Impact Assessment, edited by: Marchetti, M. and Rivas, V., A. A. Balkema, Rotterdam, 31-47, 2001.

Chung, C. F. and Fabbri, A. G.: Validation of spatial prediction models for landslide hazard mapping, Nat. Hazards, 30, 451472, 2003.

Chung, C. F. and Fabbri, A. G.: Systematic procedures of landslidehazard mapping for risk assessment using spatial prediction mod- 
els, in: Landslide hazard and risk, edited by: Glade, T., Anderson, M. G., and Crozier, M. J., Wiley, Chichester, 139-174, 2005.

Chung, C. F. and Glade, T.: Use of active and inactive landslides for spatial landslide hazard modeling, Geophys. Res. Abstr., 6, 2004.

Corominas, J. and Moya, J.: Reconstructing recent landslide activity in relation to rainfall in the Llobregat River basin, Eastern Pyrenees, Spain, Geomorphology, 30, 79-93, 1999.

Demoulin, A. and Glade, T.: Recent landslide activity in Manaihan, East Belgium, Landslides, 1, 305-310, 2004.

Demoulin, A., Pissart, A., and Schroeder, C.: On the origin of late Quaternary palaeolandslides in the Liege (E Belgium) area, Int. J. Earth Sci., 92, 795-805, 2003.

Dewitte O.: Kinematics of landslides in the Oudenaarde area and prediction of their reactivation: a probabilistic approach, Ph.D. thesis, University of Liège, Liège, 2006.

Dewitte, O. and Demoulin, A.: Morphometry and kinematics of landslides inferred from precise DTMs in West Belgium, Nat. Hazards Earth Syst. Sci., 5, 259-265, 2005,

http://www.nat-hazards-earth-syst-sci.net/5/259/2005/.

Ercanoglu, M. and Gokceoglu, C.: Use of fuzzy relations to produce landslide susceptibility map of a landslide prone area (West Black Sea Region, Turkey), Eng. Geology, 75, 229-250, 2004.

Fiorillo, F.: Geological features and landslide mechanisms of an unstable coastal slope (Petacciato, Italy), Eng. Geology, 67, 255267, 2003.

Glade, T. and Crozier, M. J.: A review of scale dependency in landslide hazard and risk analysis, in: Landslide hazard and risk, edited by: Glade, T., Anderson, M. G., and Crozier, M. J., Wiley, Chichester, 75-138, 2005.

Guzzetti, F., Carrara, A., Cardinali, M., and Reichenbach, P.: Landslide hazard evaluation: a review of current techniques and their application in a multi-scale study, Central Italy, Geomorphology, 31, 181-216, 1999.

Klir, G.J., and Yuan, B.: Fuzzy sets and fuzzy logic: theory and applications, Prentice Hall, New Jersey, 1995.

Lee, E. M., Hall, J. W., and Meadowcroft, I. C.: Coastal cliff recession: the use of probabilistic prediction methods, Geomorphology, 40, 253-269, 2001.

Lee, E. M., Moore, R., and McInnes, R. G.: Assessment of the probability of landslide reactivation: Isle of Wight Undercliff, UK, in: Eighth International Congress of the International Association for Engineering Geology and the Environment, edited by: Moore, D. P. and Hungr, O., A. A. Balkema, Vancouver, 13151321, 1998.

Moon, W. M.: Integration and fusion of geological exploration data: a theoretical review of fuzzy logic approach, Geosci. J., 2, 175$183,1998$.
Oreskes, N., Shrader-Frechette, K., and Belitz, K.: Verification, validation, and confirmation of numerical models in the Earth Sciences, Science, 263, 641-646, 1994.

Ost, L., Van Den Eeckhaut, M., Poesen, J., and VanmaerckeGottigny, M. C.: Characteristics and spatial distribution of large landslides in the Flemish Ardennes (Belgium), Zeitschrift für Geomorphologie, 47, 329-350, 2003.

Poesen, J., Nachtergaele, J., Verstraeten, G., and Valentin, C.: Gully erosion and environmental change: importance and research needs, Catena, 50, 91-133, 2003.

Polemio, M. and Sdao, F.: The role of rainfall in the landslide hazard: the case of the Avigliano urban area (Southern Apennines, Italy), Eng. Geology, 53, 297-309, 1999.

Reichenbach, P., Ardizzone, F., Cardinali, M., Galli, M., Guzzetti, F., and Carrara, A.: Validation of a landslide susceptibility model using event inventory maps, Geophys. Res. Abstr., 7, 2005.

Soeters, R. and van Westen, C. J.: Slope instability recognition, analysis, and zonation, in: Landslides: investigation and mitigation, edited by: Turner, A. K. and Schuster, R. L., Transportation Research Board, Special Report 247, National Research Council, National Academy Press, Washington D.C., 129-177, 1996.

SPMS: Spatial Prediction Modeling System user's guide, Ottawa, 2003.

Tangestani, M. H.: Landslide susceptibility mapping using the fuzzy gamma approach in a GIS, Kakan catchment area, southwest Iran, Australian J. Earth Sci., 51, 439-450, 2004.

Van Den Eeckhaut, M., Poesen, J., Verstraeten, G., Vanacker, V., Moeyersons, J., Nyssen, J., and van Beek, L. P. H.: The effectiveness of hillshade maps and expert knowledge in mapping old deep-seated landslides, Geomorphology, 67, 351-363, 2005.

Varnes, D. J.: Landslide hazard zonation: a review of principles and practice, Nat. Hazard Series, 3, UNESCO Press, Paris, 1984.

Vaunat, J. and Leroueil, S.: Analysis of post-failure slope movements within the framework of hazard and risk analysis, Nat. Hazards, 26, 83-109, 2002.

Zadeh, L. A.: Fuzzy sets, IEEE Information and Control, 8, 338353, 1965.

Zadeh, L. A.: Probability measures of Fuzzy events, J. Math. Anal. Appl., 23, 421-427, 1968.

Zadeh, L. A.: Fuzzy sets as a basis for theory of possibility, Fuzzy Sets and Systems, 1, 3-28, 1978.

Zimmermann, H.-J.: Fuzzy set theory and its application. Kluwer Academic Publisher, Dordrecht, 1991.

Zimmermann, H.-J. and Zysno, P.: Latent connectives in human decision making, Fuzzy Sets and Systems, 4, 37-51, 1980. 